\title{
Characterization of Fe(II) oxidizing bacterial activities and communities at two acidic Appalachian coalmine drainage-impacted sites
}

\author{
John M Senko ${ }^{1}$, Pauline Wanjugi ${ }^{2}$, Melanie Lucas ${ }^{1}$, Mary Ann Bruns ${ }^{2}$ \\ and William D Burgos ${ }^{1}$ \\ ${ }^{1}$ Department of Civil and Environmental Engineering, The Pennsylvania State University, PA, USA \\ and ${ }^{2}$ Department of Crop and Soil Sciences, The Pennsylvania State University, PA, USA
}

\begin{abstract}
We characterized the microbiologically mediated oxidative precipitation of $\mathrm{Fe}$ (II) from coalminederived acidic mine drainage (AMD) along flow-paths at two sites in northern Pennsylvania. At the Gum Boot site, dissolved Fe(II) was efficiently removed from AMD whereas minimal Fe(II) removal occurred at the Fridays-2 site. Neither site received human intervention to treat the AMD. Culturable $\mathrm{Fe}$ (II) oxidizing bacteria were most abundant at sampling locations along the AMD flow path corresponding to greatest Fe(II) removal and where overlying water contained abundant dissolved $\mathrm{O}_{2}$. Rates of $\mathrm{Fe}$ (II) oxidation determined in laboratory-based sediment incubations were also greatest at these sampling locations. Ribosomal RNA intergenic spacer analysis and sequencing of partial 16S rRNA genes recovered from sediment bacterial communities revealed similarities among populations at points receiving regular inputs of $\mathrm{Fe}(\mathrm{II})$-rich $\mathrm{AMD}$ and provided evidence for the presence of bacterial lineages capable of $\mathrm{Fe}(\mathrm{II})$ oxidation. A notable difference between bacterial communities at the two sites was the abundance of Chloroflexi-affiliated 16S rRNA gene sequences in clone libraries derived from the Gum Boot sediments. Our results suggest that inexpensive and reliable AMD treatment strategies can be implemented by mimicking the conditions present at the Gum Boot field site.
\end{abstract}

The ISME Journal (2008) 2, 1134-1145; doi:10.1038/ismej.2008.60; published online 12 June 2008

Subject Category: geomicrobiology and microbial contributions to geochemical cycles

Keywords: acidic mine drainage; iron; Fe(II) oxidizing bacteria

\section{Introduction}

An estimated $10000 \mathrm{~km}$ of streams in the Appalachian coal mining region of the United States are adversely impacted by acidic mine drainage (AMD) that emanates from abandoned and operating coalmines (Herlihy et al., 1990). The AMD arises when metal sulfides (primarily coal deposit-associated pyrite) come in contact with oxygenated water resulting in sulfuric acid production by the biogeochemical oxidation of reduced sulfur species (Baker and Banfield, 2003). These acidic fluids contain high concentrations of dissolved metals due to leaching of metal-containing minerals. The dissolved metal in Appalachian coalmine drainage of greatest concern is $\mathrm{Fe}(\mathrm{II})$, and the most prominent

Correspondence: JM Senko, Department of Civil and Environmental Engineering, The Pennsylvania State University, 212 Sackett Building, University Park, PA 16802, USA.

E-mail: senko@engr.psu.edu

Received 7 May 2008; accepted 19 May 2008; published online 12 June 2008 feature of AMD-impacted surface waters is the appearance of 'yellowboy,' which is an Fe(III) (hydr)oxide precipitate produced when Fe(II)-rich AMD waters enter circumneutral streams (Pennsylvania Department of Environmental Protection (PA-DEP), 1999). The relatively high $\mathrm{pH}$ (5.5-8.0) and dissolved $\mathrm{O}_{2}$ concentration in surface waters allows rapid abiotic oxidation of dissolved Fe(II) and hydrolysis of Fe(III) (Stumm and Morgan, 1996) as depicted in Equations 1 and 2, respectively:

$$
\begin{gathered}
\mathrm{Fe}^{2+}+0.25 \mathrm{O}_{2}+\mathrm{H}^{+} \rightarrow \mathrm{Fe}^{3+}+0.5 \mathrm{H}_{2} \mathrm{O} \\
\mathrm{Fe}^{3+}+3 \mathrm{H}_{2} \mathrm{O} \rightarrow \mathrm{Fe}(\mathrm{OH})_{3}+3 \mathrm{H}^{+}
\end{gathered}
$$

Yellowboy coats algae, plants, macroinvertebrates and sediments in the stream beds, leaving long stretches of 'dead' streams. Therefore, prior to its entry into nearby surface waters, two distinct and critical treatment objectives for Appalachian coalmine-derived AMD are (1) neutralization of low $\mathrm{pH}$ waters and (2) removal of Fe. 
'Active treatment' technologies require diversion and collection of water followed by addition of alkaline material before release (Pennsylvania Department of Environmental Protection (PA-DEP), 1999). While these approaches are quite reliable, they involve high energy costs and require feedback control for chemical addition, operator supervision and metal sludge collection and disposal. These requirements make active treatment quite expensive and impractical: the treatment of AMD that may emanate from abandoned coalmines for hundreds of years. Therefore, 'passive treatment' technologies are preferred due to the low cost of maintenance and materials. A common strategy for passively treating AMD from Appalachian coalmines is to divert AMD through limestone beds or channels (Cravotta and Trahan, 1999; Pennsylvania Department of Environmental Protection (PA-DEP), 1999; Nengovhela et al., 2004; Johnson and Hallberg, 2005). Limestone dissolution neutralizes acidic fluids, which enhances the kinetics of $\mathrm{Fe}(\mathrm{II})$ oxidation (Equation 1) and $\mathrm{Fe}(\mathrm{III})$ hydrolysis (Equation 2) so that $\mathrm{Fe}$ removal is accomplished by precipitation of $\mathrm{Fe}(\mathrm{III})$ (hydr)oxides (Cravotta and Trahan, 1999; Pennsylvania Department of Environmental Protection (PADEP), 1999; Johnson and Hallberg, 2005). Although such precipitation helps remove dissolved Fe(II), these Fe(III) (hydr)oxide precipitates also coat limestone surfaces (commonly called 'armoring'), limiting further limestone dissolution and neutralization capacity and may also clog limestone beds (Pennsylvania Department of Environmental Protection (PA-DEP), 1999; Rose et al., 2004; Weaver et al., 2004).

To limit armoring and clogging, dissolved Fe may be removed from AMD before waters are neutralized with limestone. In the $\mathrm{pH}$ range typical of Appalachian AMD (2.5-4.5) (Cravotta et al., 1999), the abiotic oxidation of Fe(II) (Equation 1) is kinetically limited, but hydrolysis and precipitation of $\mathrm{Fe}(\mathrm{III})$ (Equation 2) will still occur (Stumm and Morgan, 1996). Under such conditions, acidophilic Fe(II) oxidizing bacteria (Fe(II)OB) may catalyze Fe(II) oxidation, allowing for the oxidative precipitation of $\mathrm{Fe}$ from AMD effluents at low $\mathrm{pH}$ (Olem and Unz, 1977; Unz et al., 1979; Kirby et al., 1999; Nengovhela et al., 2004; Johnson and Hallberg, 2005; Nicormat et al., 2006a,b). This Fe-free water may then be neutralized using limestone before it is released into nearby streams (Nengovhela et al., 2004). We have identified an AMD impacted system in north-central Pennsylvania (called Gum Boot), in which Fe(II) is effectively removed from AMD at low $\mathrm{pH}$ with no human intervention, and we hypothesized that this was due to $\mathrm{Fe}(\mathrm{II})$ oxidizing bacterial activity.

A better understanding of geomicrobiological processes in the Gum Boot system may be used to develop technologies suitable for stimulating microbiologically mediated oxidative precipitation of $\mathrm{Fe}$ at low $\mathrm{pH}$ in other AMD-impacted systems. To gain insight into the mechanisms by which this process occurs, we characterized AMD water chemistry, microbial activities and microbial communities in Gum Boot Run system and compared them to those of an AMD discharge system (called Fridays-2) that exhibits similar chemical and flow characteristics, but where little $\mathrm{Fe}$ is removed from the water.

\section{Materials and methods}

\section{Site description and sampling techniques}

Two AMD-impacted systems were characterized in this study: Gum Boot (GB) and Fridays-2 (FR). Flow rates at the two systems are relatively low in comparison to flow rates at other sites in the Appalachian coal mining region of Pennsylvania, which can be as high as $133000 \mathrm{lmin}^{-1}$ (Cravotta, 2008). The GB system is located in McKean County, Pennsylvania $\left(41^{\circ} 41^{\prime} 02^{\prime \prime} \mathrm{N} ; 78^{\circ} 29^{\prime} 37^{\prime \prime} \mathrm{W}\right)$. AMD at the GB system emerges at the crest of a hill with a flow rate of approximately $50 \mathrm{lmin}^{-1}$ and flows as a sheet $(0.5 \mathrm{~cm}$ deep) over an Fe(III)-rich (approximately $60 \% \mathrm{Fe}_{2} \mathrm{O}_{3}$ by mass) mound that contains goethite as the predominant crystalline mineral phase (X-ray diffraction (XRD) data not shown). After emergence, water flows approximately $18 \mathrm{~m}$ downhill before flowing underground, re-emerging at a point approximately $48 \mathrm{~m}$ downhill from the source and finally entering a pool at the foot of the hill $127 \mathrm{~m}$ from the source (Supplementary Figure S1). Water from the pool ultimately discharges into nearby Gum Boot run water and sediment samples were collected in October 2005, February 2006, May 2006 and July 2006 (fall, winter, spring and summer sampling events, respectively) at discrete sampling locations $0 \mathrm{~m}$ (AMD emergence point), 2, 9, 15, 60, 95 and $127 \mathrm{~m}$ (in the pool at the foot of the hill) downstream from the AMD emergence point (Supplementary Figure S1). Macroscopic photoeukaryotic organisms that are often observed in AMDimpacted systems (Brake et al., 2002) were not present at the GB system. No soil was evident in the GB AMD flow path within the first $18 \mathrm{~m}$ from emergence (Supplementary Figure S1). Water temperatures across the AMD flow path varied seasonally, with temperatures as high as $29^{\circ} \mathrm{C}$ observed in warmer months (Supplementary Figure S3).

The Fridays-2 system is located in Clearfield County, Pennsylvania $\left(41^{\circ} 14^{\prime} 34^{\prime \prime} \mathrm{N} ; 78^{\circ} 32^{\prime} 28^{\prime \prime}\right.$ $\mathrm{W})$. AMD at the FR system emerges at a former mine entrance at a flow rate of approximately $136 \mathrm{lmin}^{-1}$ and flows as a $0.5 \mathrm{~cm}$ thick sheet in a manner similar to that of the GB system. The Fe(III) (hydr)oxide-rich mound at the FR system is also approximately $1 \mathrm{~m}$ thick, but the predominant mineral phase is schwertmannite (XRD data not shown). AMD flows over this mound approximately $10 \mathrm{~m}$ before entering an adjacent unnamed creek (Supplementary Figure S2). Yellowboy was apparent in creek sediments downstream of AMD entrance into the creek, but no Fe(III) was apparent upstream of the point of AMD 
entry. Samples were collected in February, May and July 2006 (winter, spring and summer sampling events, respectively) at discrete sampling locations $0 \mathrm{~m}$ (in the AMD source), 3, 8 and $10 \mathrm{~m}$ from the AMD emergence point (Supplementary Figure S2). Samples were also collected from the unnamed creek upstream and downstream of AMD entry (Supplementary Figure S2). As with the GB system, macroscopic photoeukaryotic organisms were not observed. The water temperature of the FR system remained constant seasonally (Supplementary Figure S3).

Sediments for laboratory-scale incubations, bacterial enumerations and nucleic acid-based microbial community characterization were collected with sterile spatulas and placed in sterile centrifuge tubes or whirl-pak bags. Sediments were collected from the top $2 \mathrm{~cm}$ of sediment at each location. Water samples were filter-sterilized $(0.2 \mu \mathrm{m})$ in the field. Samples intended for sulfate analysis were not preserved. Samples for analysis of soluble Fe were preserved with $0.5 \mathrm{M} \mathrm{HCl}$, and samples for analysis of other metals were preserved with $0.5 \mathrm{M} \mathrm{HNO}_{3}$. All samples were stored on ice for transport to the laboratory, except for samples intended for nucleic acid-based microbial community analysis, which were transported on dry ice. Dissolved oxygen concentrations (DO), temperature and $\mathrm{pH}$ were determined in the field using portable meters.

\section{Enumeration of culturable Fe(II) oxidizing bacteria}

After collection, samples intended for microbial enumerations were stored at $4{ }^{\circ} \mathrm{C}$ for no more than 4 days before initiation of enumeration studies. Fe(II) oxidizing bacteria (Fe(II)OB) were enumerated by a plate counting technique described by Johnson (1995). This medium (called FeTSBo) contained $14 \mathrm{mM}\left(\mathrm{NH}_{4}\right)_{2} \mathrm{SO}_{4}, 2 \mathrm{mM} \mathrm{MgSO}{ }_{4}, 0.25 \mathrm{gl}^{-1}$ trypticase soy broth and the $\mathrm{pH}$ was adjusted to 3.5 with $\mathrm{H}_{2} \mathrm{SO}_{4}$. Agarose $\left(20 \mathrm{gl}^{-1}\right.$; high gel strength from EMD Chemicals Inc.; Gibbstown, NJ, USA) was used as a solidifying agent. $\mathrm{FeSO}_{4}(25 \mathrm{mM})$ was provided as an electron donor. Since products of the hydrolysis of agarose in the acidic medium may inhibit the growth of Fe(II) oxidizing bacteria, plates were prepared with two layers of medium. The underlayer was inoculated $(2.5 \% \mathrm{vol} / \mathrm{vol})$ with the acidophilic organoheterotrophic bacterium Acidophilium organovorum (that was cultivated on the medium described above with galactose as an electron donor and carbon source) before pouring. The overlayer received no inoculum before pouring. The inclusion of $A$. organovorum served to minimize the accumulation of agarose hydrolysis products. Sediments were suspended in agarose-free medium (approximately $0.2 \mathrm{~g}$ sediment/ $5 \mathrm{ml}$ medium; described above), homogenized by vortexing, serially diluted and spread on plates. Fe(II)OB colony forming units (CFU) were indicated by the formation of red-orange colonies.
To obtain Fe(II)OB cultures, colonies were transferred to agarose-free FeTSBo or American Type Culture Collection (ATCC) medium 2039 ('Acidithiobacillus ferrooxidans medium'; $\mathrm{pH}$ 2.3). One culture grew sufficiently on ATCC medium 2039 and was successfully transferred eight times, after which a cell pellet was obtained for DNA extraction with a Lysis Plus Mini Kit (Qiagen Inc., Valencia, CA, USA), and processed as described below.

\section{Sediment incubations}

Sediments collected from the sampling locations described above were incubated with synthetic acidic mine drainage (SAMD) in $160 \mathrm{ml}$ serum bottles with air in the headspace and sealed with thin Teflon-coated stoppers. SAMD contained $7 \mathrm{mM}$ $\mathrm{FeSO}_{4}, 5 \mathrm{mM} \mathrm{CaSO}, 4 \mathrm{mM} \mathrm{MgSO}{ }_{4}, 1 \mathrm{mM} \mathrm{Na}_{2} \mathrm{SO}_{4}$, $0.5 \mathrm{mM} \quad \mathrm{Al}_{2}\left(\mathrm{SO}_{4}\right)_{3}, \quad 0.4 \mathrm{mM} \quad \mathrm{MnSO}_{4}$ and $0.1 \mathrm{~mm}$ $\left(\mathrm{NH}_{4}\right)_{2} \mathrm{Fe}\left(\mathrm{SO}_{4}\right)_{2}$. The $\mathrm{pH}$ of SAMD was adjusted to 3.5 with $\mathrm{H}_{2} \mathrm{SO}_{4}$. Where appropriate for abiotic controls, biological activity was deactivated by the addition of $1 \%$ formaldehyde, $0.1 \%$ sodium azide, or autoclaving. To measure Fe(II) oxidation kinetics, $8 \mathrm{~g}$ of sediments were combined with $20 \mathrm{ml}$ of SAMD, leaving $140 \mathrm{ml}$ of headspace and an estimated $1.2 \mathrm{mmol} \mathrm{O}_{2} /$ bottle, with approximately $0.14 \mathrm{mmol}$ $\mathrm{Fe}(\mathrm{II}) /$ bottle. The $\mathrm{pH}$ was measured at the beginning and end of the incubations in sacrificed sedimentSAMD slurries. In initial experiments to determine effective abiotic controls, $10 \mathrm{~g}$ of sediment were incubated with $50 \mathrm{ml}$ of SAMD. For these experiments, a larger volume was used to allow larger sample sizes so that $\mathrm{pH}$ could be determined throughout the experiment. Bottles contained approximately $0.9 \mathrm{mmol} \mathrm{O}_{2}$ and $0.35 \mathrm{mmol} \mathrm{Fe}(\mathrm{II})$.

Incubations were periodically sampled using a needle and syringe. For experiments to determine the contribution of microbiological activity to oxidative precipitation of $\mathrm{Fe}$, dissolved $\mathrm{Fe}(\mathrm{II})$ and $\mathrm{Fe}(\mathrm{III})$ were measured in the soluble fraction and total $\mathrm{Fe}(\mathrm{II})$ in the $0.5 \mathrm{~m} \mathrm{HCl}$-extractable fraction (Lovley and Phillips, 1987) by 1.10 phenanthroline and ferrozine assay (described below). We found that dissolved $\mathrm{Fe}(\mathrm{III})$ did not contribute to the total dissolved Fe detected and that adsorption of Fe(II) to sediments was minimal. Therefore, dissolved Fe(II) was quantified by ferrozine assay through the remainder of the study. First order Fe(II) oxidation rate constants $(\mathrm{k})$ were determined by linear least squares regression fitting of $\ln [\mathrm{Fe}(\mathrm{II})]$ versus time using the following equation:

$$
\operatorname{In}\left[\mathrm{Fe}(\mathrm{II})_{\mathrm{t}}\right]=-\mathrm{kt}+\operatorname{In}\left[\mathrm{Fe}(\mathrm{II})_{\text {initial }}\right]
$$

\section{Nucleic acid-based bacterial community} characterization

All samples for nucleic acid-based microbial community analysis were stored at $-80^{\circ} \mathrm{C}$ until DNA was extracted. Direct extraction of DNA from 
Fe(III)-rich sediments proved difficult, so Fe(III) was removed from samples with $0.3 \mathrm{M}$ ammonium oxalate $(\mathrm{pH} 3.0)$ as described by Nicormat et al. (2006a). Samples were incubated in ammonium oxalate solution for $1 \mathrm{~h}$ at room temperature, centrifuged, the supernatant was decanted and fresh ammonium oxalate solution was added. Removal of $\mathrm{Fe}(\mathrm{III})$ was indicated by a lack of orange color in the supernatant and was generally achieved after six washes. The remaining pellet (400-1000 mg (wet) recovered from $6 \mathrm{~g}$ of wet sediment) was then washed three times with TE buffer $(10 \mathrm{mM}$ Trishydroxymethylaminomethane (Tris) and $1 \mathrm{~mm}$ ethylene diamine tetraacetic acid (EDTA), $\mathrm{pH}$ 8.0). Fe(III) was removed from $\mathrm{Fe}(\mathrm{II}) \mathrm{OB}$ cultures using the same techniques. Fe(III)-free samples were stored at $-80^{\circ} \mathrm{C}$ before further processing. DNA was extracted from Fe(III)-free sediments using the MoBio UltraClean Soil DNA extraction kit (MoBio Laboratories Inc., Carlsbad, CA, USA). Ribosomal intergenic spacer analysis (RISA)-PCR was performed as described by Castillo-Gonzalez and Bruns (2005) using bacteria-specific primers based on Escherichia coli positions 16S-926f (5'-AAAGTYAAAKGAATT GACGG-3') and 23S-115r (5'-GGGTTBCCCCATT CGG-3') (Lane, 1991) purchased from Invitrogen Corp (Carlsbad, CA, USA). PCR mixtures contained $2 \mu \mathrm{l}$ of a 1:5 dilution of sediment-derived DNA, $5 \mu \mathrm{l}$ of $10 \times$ HotMaster PCR buffer with $25 \mathrm{mM} \mathrm{MgCl}_{2}$ (Eppendorf Corp., Westbury, NY, USA), $1 \mu \mathrm{l}$ of $10 \mathrm{mM}$ dNTPs, $3 \mu \mathrm{l}$ (each) of $10 \mathrm{mM}$ primer, $0.5 \mu \mathrm{l}$ of $50 \mathrm{mg} \mathrm{ml}^{-1}$ bovine serum albumin, $0.25 \mu \mathrm{l}$ of $5 \mathrm{u}^{-1}$ HotMaster Taq polymerase (Eppendorf Corp., Westbury, NY, USA) and $35.25 \mu \mathrm{l}$ of molecular biology grade water. PCR cycling in a 2400 PerkinElmer thermocycler consisted of an initial denaturation step for $5 \mathrm{~min}$ at $94{ }^{\circ} \mathrm{C}$ and 30 cycles of $94{ }^{\circ} \mathrm{C}$ for $0.5 \mathrm{~min}, 54^{\circ} \mathrm{C}$ for $0.5 \mathrm{~min}$ and $72^{\circ} \mathrm{C}$ for $1 \mathrm{~min}$, followed by a final extension step at $72^{\circ} \mathrm{C}$ for $7 \mathrm{~min}$. RISA-PCR products were separated based on DNA fragment size by agarose gel electrophoresis ( $2 \%$ agarose in Tris-acetate-EDTA buffer $(0.4 \mathrm{M}$ Tris, $0.2 \mathrm{M}$ acetic acid and $0.01 \mathrm{M}$ EDTA), and $5 \mu \mathrm{g} \mathrm{ml}^{-1}$ ethidium bromide) at $85 \mathrm{~V}$ for $1.5 \mathrm{~h}$. Ethidium bromide-stained DNA bands were visualized under UV illumination and photographed with EpiChemi II equipment (UVP Inc., Upland, CA, USA). For 16S rRNA gene-based identification of cultured Fe(II)OB, PCR products were cloned directly into TOPO-TA vector (Invitrogen) following the manufacturer's instruction.

To obtain partial 16S rRNA gene sequences from bands in the RISA gel, individual bands were excised from the gel, suspended in $50 \mu \mathrm{l}$ of molecular biology grade water and macerated. The $16 \mathrm{~S}$ rRNA gene portions of the RISA amplicons were amplified in $50 \mu \mathrm{l}$ reaction mixtures as described above using bacteria-specific primers based on E. coli positions 16S-926f (5'-AAAGTYAAAKGAATT GACGG-3') and 16S-1492r (5'-TACGGYTACCTTGT TACGACTT- $3^{\prime}$ ). Fresh PCR products were directly cloned into TOPO-TA vector as described above. Six PCR insert-containing clones were selected per RISA band, grown to late log phase in Luria-Bertani broth (Atlas, 2004) that was supplemented with $75 \mu \mathrm{g}$ ampicillin $\mathrm{ml}^{-1}$, and stored in $12 \%$ glycerol at $-80^{\circ} \mathrm{C}$ before further processing. PCR insert-containing TOPO-TA vectors were prepared for sequencing using TempliPhi rolling circle amplification (GE Healthcare Bio-Sciences Corp., Piscataway, NJ, USA) in 96-well plate formats according to the manufacturer's instructions. DNA sequencing was performed at The Pennsylvania State University's DNA sequencing facility using an ABI Hitachi 3730XL DNA Analyzer.

For phylogenetic placement, 16S rRNA gene sequences were initially analyzed using Basic Local Alignment Search Tool (BLAST) (Altschul et al., 1997). Sequences were checked for chimeras using the Ribosomal Database Project II's chimera detection function (Cole et al., 2003). Sequences with more than $90 \%$ similarity were considered to belong to the same operational taxonomic unit (OTU). OTUs were assigned phylum-level classifications using the Ribosomal Database Project II's classifier function (Wang et al., 2007). Relative frequencies of detected taxa at GB and FR were estimated based on combined pools of sequences from excised RISA bands for each site (two RISA lanes for GB and three lanes for FR). Sequences obtained in this work and those obtained from GenBank were downloaded into a Geneious 3.0 software environment (Drummond et al., 2007). Sequences were aligned within the Geneious environment using the ClustalW algorithm (Thompson et al., 1994), and evolutionary distance trees (neighbor-joining algorithm with Jukes-Cantor corrections) were produced using Geneious 3.0. Evolutionary distance trees were produced as described above using 16S rRNA gene sequences from the GB and FR systems and those obtained from GenBank with Aquifex pyrophilus (GenBank accession number M83548) or Limnothrix redekei (GenBank accession number AJ58007) as outgroups.

\section{Chemical analytical techniques}

Fe(II) was quantified with ferrozine (Lovley and Phillips, 1987) or by 1,10-phenanthroline assay (Tamura et al., 1974). For the quantification of dissolved $\mathrm{Fe}(\mathrm{III})$, samples were incubated in an anoxic glovebag for approximately $16 \mathrm{~h}$ with $0.25 \mathrm{M}$ hydroxylamine-HCl/ $0.25 \mathrm{M} \mathrm{HCl}$ (Lovley and Phillips, 1987) to reduce $\mathrm{Fe}(\mathrm{III})$ to $\mathrm{Fe}(\mathrm{II})$, which was then quantified by 1,10-phenanthroline. Sulfate was quantified by ion chromatography on a Dionex 100 system fitted with an AS4A column with conductivity detection (Dionex Corp., Sunnyvale, CA, USA). Dissolved Al, Ca, K, Mg, Mn, Na, Si, and Fe content of sediments were quantified by inductively coupled plasma emission spectrometry using a Leeman Labs PS3000UV ICP-AES (Teledyne Leeman Labs, Hudson, NH, USA). Total organic carbon 
Table 1 Dissolved constituents and physical characteristics of emergent AMD at GB and FR

\begin{tabular}{lrr}
\hline & Gum boot & Fridays-2 \\
\hline $\mathrm{Al}(\mu \mathrm{M})$ & 52 & 4 \\
$\mathrm{Ca}(\mu \mathrm{M})$ & 344 & 232 \\
$\mathrm{~K}(\mu \mathrm{M})$ & 82 & 18 \\
$\mathrm{Mg}(\mu \mathrm{M})$ & 313 & 103 \\
$\mathrm{Mn}(\mu \mathrm{M})$ & 51 & $\mathrm{BDL}$ \\
$\mathrm{Na}(\mu \mathrm{M})$ & 530 & 174 \\
$\mathrm{Si}(\mu \mathrm{M})$ & 436 & 129 \\
$\mathrm{Fe}(\mathrm{II})(\mu \mathrm{M})$ & 869 & 1150 \\
$\mathrm{Fe}(\mathrm{III})(\mu \mathrm{M})$ & 197 & 142 \\
$\mathrm{SO}{ }_{4}^{2-}(\mu \mathrm{M})$ & 987 & 3961 \\
$\mathrm{D} . \mathrm{O} .(\mu \mathrm{M})$ & $\mathrm{BDL}$ & $\mathrm{BDL}$ \\
$\mathrm{pH}$ & 4.10 & 4.50 \\
Temperature $\left({ }^{\circ} \mathrm{C}\right)$ & 12 & 10 \\
Flow rate $\left(\mathrm{lmin}^{-1}\right)$ & 50 & 136 \\
\end{tabular}

BDL, below detection limit.

Dissolved species were quantified as described in the text.

(TOC) was measured using a Shimadzu TOC-V total organic carbon analyzer (Shimadzu Corp., Columbia, MD, USA).

Nucleotide sequence accession numbers

16S rRNA gene sequences obtained in this study have been deposited under GenBank accession numbers EU220838 to EU220922.

\section{Results and discussion}

To understand controlling factors on oxidative removal of $\mathrm{Fe}$ from AMD at low $\mathrm{pH}$, we characterized water chemistry, microbial activities and microbial communities associated with two AMD discharges. Fe(II) has historically been observed to be effectively removed from AMD emanating from the Gum Boot (GB) discharge, but not from FR AMD, which led us to designate the GB system as a $\mathrm{Fe}$ removal $(+)$ system, and the FR system as an $\mathrm{Fe}$ removal (-) system. Neither of these sites have received substantial human intervention to remove Fe from the AMD, and waters emerging from both sites exhibit roughly similar chemical and flow characteristics even though the AMD flow rate at the FR system is greater than that of the GB system (Table 1).

\section{$A M D$ chemistry at $G B$ and FR}

Dissolved Fe(II) was completely removed from GB AMD over a distance of approximately $15 \mathrm{~m}$ (Figure 1a). At sampling locations greater than $48 \mathrm{~m}$ from AMD emergence (Supplementary Figure S1), dissolved $\mathrm{Fe}(\mathrm{II})$ concentrations were low (Figure 1a). The lack of soil and the thick deposits of Fe(III) (hydr)oxide-rich sediments associated with the first $15 \mathrm{~m}$ of the GB AMD flow path led us to classify the sediments in this region of the flow path

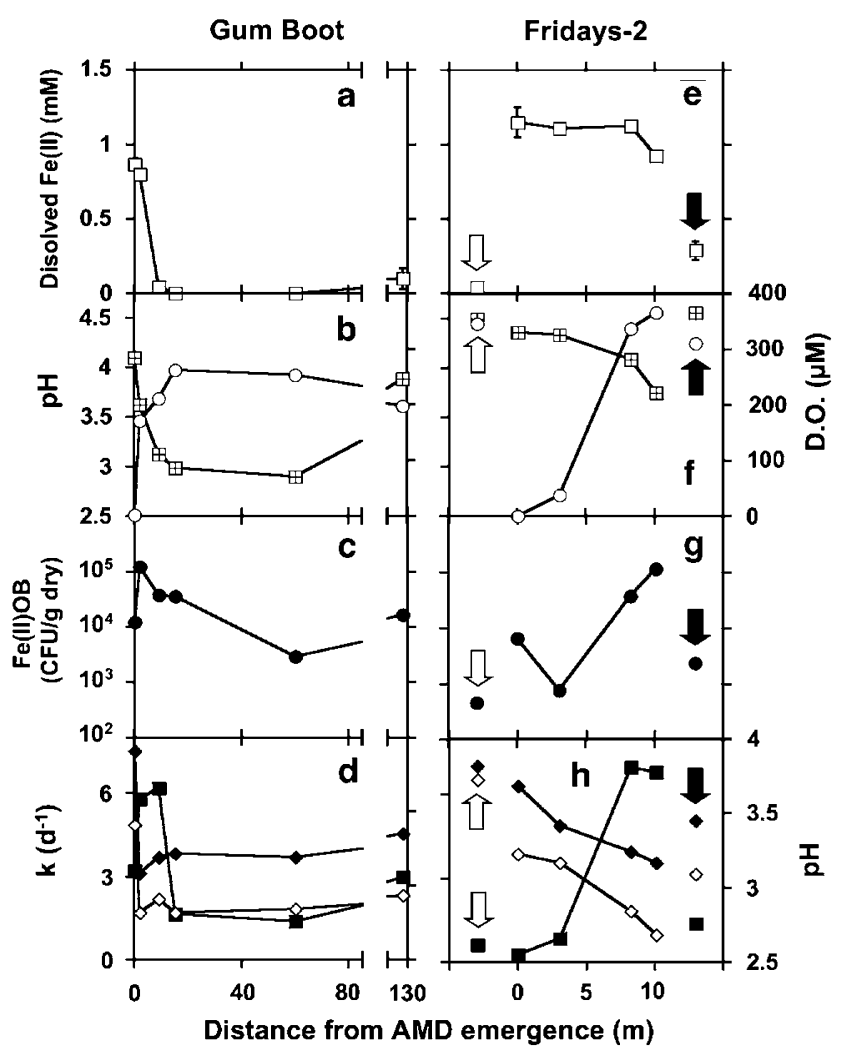

Figure 1 Characterization of water chemistry, abundance of culturable Fe(II) oxidizing bacteria (Fe(II)OB), and microbial activities from discrete sampling locations in the GB and FR systems. Dissolved Fe(II) concentrations ( $\square$ ) are shown in panels $\mathbf{a}$ and $\mathbf{e} ; \mathrm{pH}(\otimes)$ and dissolved oxygen concentrations $(O)$ are shown in panels $\mathbf{b}$ and $\mathbf{f}$; numbers of culturable Fe(II)OB ( $)$ ) (as indicated by colony forming units CFU) are shown in $\mathbf{c}$ and $\mathbf{g}$; first order rate constants (k) of $\mathrm{Fe}(\mathrm{II})$ oxidation ( $\mathbf{\square}$ ) observed in sediment incubations and starting $(\diamond)$ and ending $(\diamond) \mathrm{pH}$ of the incubations are shown in panels $\mathbf{d}$ and $\mathbf{h}$. In the Fridays- 2 panels, upstream and downstream sampling locations in the unnamed creek are pointed out using white arrows and black arrows, respectively. Error bars represent one s.d.

as those that received regular inputs of unaltered (that is dissolved Fe(II)-rich and relatively low $\mathrm{pH}$ ) AMD. After emergence, initially anoxic AMD was aerated within approximately $2 \mathrm{~m}$ of the AMD emergence point, and the $\mathrm{pH}$ of the AMD decreased concurrently with Fe(II) removal (Figures 1a and b), suggesting that $\mathrm{Fe}(\mathrm{II})$ was oxidized to $\mathrm{Fe}(\mathrm{III})$, with subsequent hydrolysis and precipitation. In the pool $127 \mathrm{~m}$ downstream from AMD emergence (Supplementary Figure S1), DO concentration was lower and Fe(II) concentration was higher (Figures 1a and $\mathrm{b}$ ), suggesting that anaerobic processes were occurring in this pool.

$\mathrm{Fe}(\mathrm{II})$ removal was not as efficient in the FR system as it was in the GB system (Figure 1e), and AMD at the FR system traveled a greater distance (approximately $8 \mathrm{~m}$ ) before it was well aerated (Figure 1f) compared to the GB system, perhaps due to the higher flow rate and/or other hydrodynamic factors. No soil was evident in the FR 
system except for sediments in the unnamed creek (Supplementary Figure S2), leading us to designate AMD flowing over the first $10 \mathrm{~m}$ of the FR flow path as unaltered. The presence of the thick Fe(III) (hydr)oxide-rich sediments in the FR system suggested that $\mathrm{Fe}(\mathrm{II})$ was oxidatively precipitated there, but the persistence of dissolved Fe(II) suggested that this process does not occur as rapidly in the FR system as in the GB system.

One explanation for the more efficient removal of Fe(II) from AMD at the GB system compared to the FR system is the greater mass transfer of $\mathrm{Fe}(\mathrm{II})$ into the FR system than the GB system due to the 2.7-fold greater flow rate of AMD at FR. However, a flow ratenormalized comparison of $\mathrm{Fe}(\mathrm{II})$ removal efficiency suggests that this is not the case. At GB, Fe(II) is removed from solution at a rate of approximately $0.09 \mathrm{mM} \mathrm{m}^{-1}$ at a flow rate of $50 \mathrm{lmin}^{-1}$ (Figure 1a). If a similar rate of $\mathrm{Fe}(\mathrm{II})$ removal was occurring at the FR system (where water flows at a rate of $136 \mathrm{lmin}^{-1}$ ), we would expect that approximately $0.7 \mathrm{mM} \mathrm{Fe}$ (II) would be removed from FR AMD within $10 \mathrm{~m}$. This was not the case with the FR system, where we observed removal of only $0.2 \mathrm{mM}$ Fe(II) from AMD within $10 \mathrm{~m}$ (Figure 1e). These considerations suggest that biogeochemical factors other than the mass transfer of $\mathrm{Fe}(\mathrm{II})$ into the FR system must influence the efficient removal of Fe(II) from AMD in that system.

\section{Assessment of biological $\mathrm{Fe}(\mathrm{II})$ oxidation}

We hypothesized that the oxidation of $\mathrm{Fe}(\mathrm{II})$ and subsequent precipitation of Fe(III) (hydr)oxides in these systems was predominantly mediated by Fe(II) oxidizing bacteria (Fe(II)OB), although the presence of Fe(III) (hydr)oxides may enhance the kinetics of abiotic Fe(II) oxidation (Dempsey et al., 2001; Park and Dempsey, 2005). To assess the role of microbiological activity in the oxidative precipitation of Fe from AMD, we incubated non-sterile sediments from the GB system with synthetic AMD (SAMD). We compared rates of $\mathrm{Fe}(\mathrm{II})$ oxidation and precipitation by non-sterile sediments to $\mathrm{Fe}(\mathrm{II})$ oxidation rates by sediments in which biological activity was deactivated by formaldehyde or sodium azide poisoning or autoclaving. We tested a variety of methods for deactivating biological activity because each method had the potential to induce physicochemical changes to the sediments that could lead to improper interpretation of abiotic or microbiologically mediated Fe(II) oxidation (Tebo, 1991; Shiller and Stephens, 2005). Oxidative precipitation of $\mathrm{Fe}$ was not observed in microbiologically deactivated incubations, regardless of the deactivation technique (Figure 2). The addition of formaldehyde to incubations altered solution chemistry less than the addition of sodium azide, which increased the solution $\mathrm{pH}$, or autoclaving, which induced the release of dissolved $\mathrm{Fe}$ and a decrease in $\mathrm{pH}$ (Figures $2 \mathrm{a}$ and b). Removal of Fe(II) from solution was only

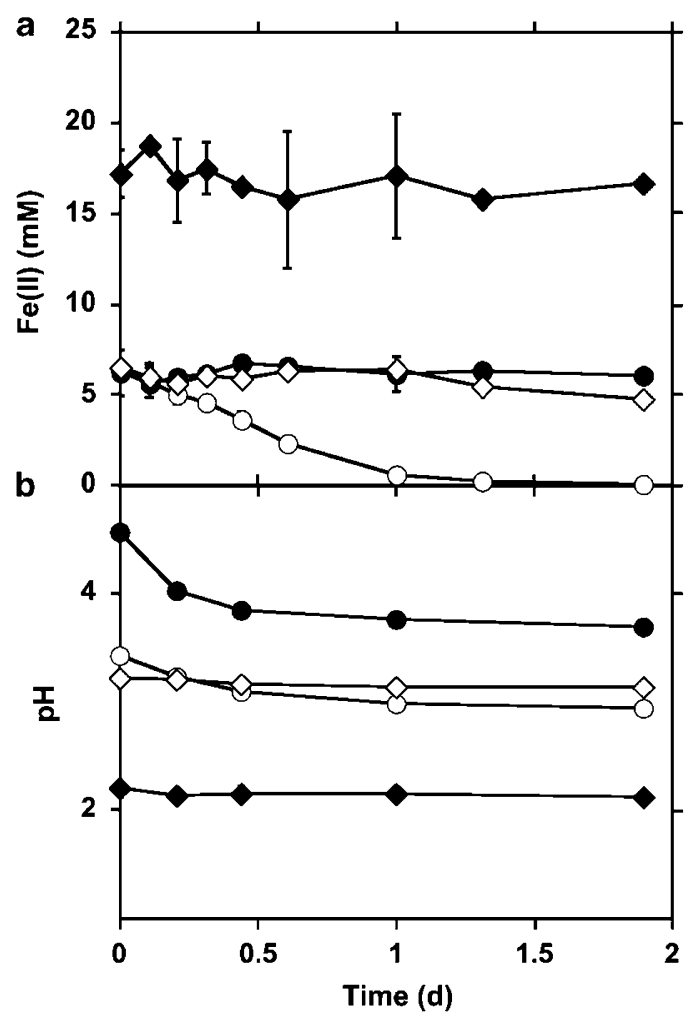

Figure 2 Fe(II) removal (a) and concurrent pH decrease (b) in non-sterile incubations containing sediments from the GB system ( $2 \mathrm{~m}$ sampling location) $(\bigcirc)$ compared to incubations that were biologically inactivated by autoclaving $(\bullet)$ or the addition of $1 \%$ formaldehyde $(\diamond)$, or $1 \mathrm{mg} / \mathrm{l}$ sodium azide $(\bullet)$. Error bars represent one s.d.

observed in non-sterile incubations (Figure 2a) and this occurred concomitantly with a decrease in $\mathrm{pH}$ (Figure 2b), suggesting that the oxidative precipitation of $\mathrm{Fe}$ in systems such as GB and FR is predominantly mediated by Fe(II)OB.

\section{Abundance and activity of $\mathrm{Fe}(\mathrm{II}) \mathrm{OB}$ in the GB and FR systems}

We hypothesized that Fe(II)OB would be most abundant in regions of the AMD flow path where oxidative precipitation of $\mathrm{Fe}$ was evident based on field measurements (that is close to the AMD emergence point at the GB system (Figure 1a), and distant from the AMD emergence point at the FR system (Figure 1e)), and that higher numbers of $\mathrm{Fe}(\mathrm{II}) \mathrm{OB}$ would correspond with faster rates of $\mathrm{Fe}(\mathrm{II})$ oxidation by sediments recovered from the respective sampling locations. Indeed, culturable Fe(II)OB were most abundant at locations in the GB and FR systems where most Fe removal was occurring as determined by field measurements (for example the GB $2 \mathrm{~m}$ and FR $10 \mathrm{~m}$ sampling locations; Figures 1c and g). Fe(II)OB were most abundant in the GB system immediately below the AMD discharge point, in contrast to relatively low numbers of $\mathrm{Fe}(\mathrm{II}) \mathrm{OB}$ at downstream locations where all Fe(II) 
had been removed (Figures 1a and c). In the FR system, Fe(II)OB were most abundant below the AMD discharge at the two most downstream sampling locations where the highest levels of dissolved oxygen were measured (Figures $1 \mathrm{f}$ and g). The numbers of $\mathrm{Fe}(\mathrm{II}) \mathrm{OB}$ in the GB and FR systems $\left(10^{3}-10^{5} \mathrm{CFUg}^{-1}\right.$ in the AMD flow paths) are comparable to those reported in a similar AMDimpacted system (Hallberg and Johnson, 2005). Attempts to culture organisms present in colonies on medium used for plate counts in liquid FeTSBo medium ( $\mathrm{pH}$ 3.5) were unsuccessful, but organisms present in colonies from GB $2 \mathrm{~m}$ could be cultured in ATCC medium 2039 ('Acidithiobacillus ferrooxidans medium'; pH 2.3). Sequencing of partial fragments of the 16S rRNA gene (E. coli positions 926-1542) of this culture revealed that it was $99 \%$ similar to $A$. ferrooxidans ATCC 27320. Thus, culturable $\mathrm{Fe}(\mathrm{II}) \mathrm{OB}$ closely related to $A$. ferrooxidans were recovered from GB sediments.

When we incubated sediments from each discrete sampling location in the GB and FR systems, we observed the highest first order rate constants $(\mathrm{k})$ of $\mathrm{Fe}(\mathrm{II})$ oxidation in sediments that harboured the highest numbers of Fe(II)OB (Figures 1c, d, g and h). These results suggest that rates of $\mathrm{Fe}(\mathrm{II})$ oxidation are dependent on the abundance of $\mathrm{Fe}(\mathrm{II}) \mathrm{OB}$ and that the availability of dissolved oxygen may exert strong control on the abundance and activity of $\mathrm{Fe}(\mathrm{II}) \mathrm{OB}$ in AMD-impacted systems.

\section{Nucleic acid-based characterization of bacterial communities in the GB and FR systems}

We hypothesized that bacterial communities present in Fe-rich sediments would exhibit community profiles dissimilar to those associated with sediments that did not receive regular inputs of unaltered AMD (that is in the $127 \mathrm{~m}$ sampling location at GB and within the unnamed creek at FR). We used RISA to assess bacterial diversity at discrete sampling locations at GB and FR. Bacterial communities associated with AMD sources and Fe(III)-rich sediments at both GB and FR exhibited considerably less diversity (as indicated by the number of bands observed in each lane) than those associated with sediments at the $127 \mathrm{~m}$ sampling location at GB and in the unnamed creek at FR (Figure 3). Similar RISA banding patterns of the GB and FR sources and Fe(III)-rich sediments suggested similarly simple community structures among these sampling locations. These observations are consistent with previous work suggesting that due to the relatively harsh chemical conditions of AMD, the diversity of microorganisms present in AMD systems is generally lower than that of less chemically 'extreme' systems (for example, soils or sediments of circumneutral pH) (Baker and Banfield, 2003; Hallberg et al., 2006). Therefore, it appears that the regular input of unaltered AMD is the primary controlling factor on the structure of microbial

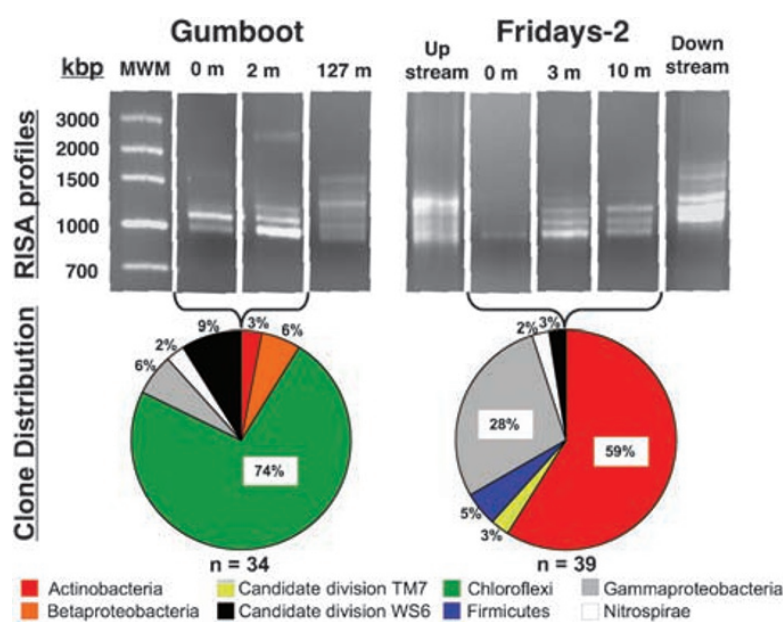

Figure 3 Ribosomal RNA intergenic spacer analysis (RISA) (top panels) and phylum-level distribution of partial bacterial 16S rRNA gene sequences observed in clone libraries recovered from the RISA gel (bottom panel) of microbial communities present in the sources and Fe(III)-rich crusts of the Gum Boot $(0$ and $2 \mathrm{~m}$ sampling locations) and Fridays- $2(0,3$, and $10 \mathrm{~m}$ sampling locations) systems. Percentages of clones obtained from excised RISA bands and affiliated with a given phylum are shown next to their respective segments in each pie chart. $\mathrm{n}$ indicates the number of clones in each 16S rRNA gene clone library.

communities in AMD-impacted systems. Microbial communities receiving unaltered AMD are similar and have the potential for rapid oxidative removal of Fe(II) from AMD, but numbers of Fe(II)OB and rates of $\mathrm{Fe}(\mathrm{II})$ oxidation may be suppressed by limited $\mathrm{O}_{2}$ availability.

Owing to the similarities in RISA banding patterns of the $\mathrm{Fe}(\mathrm{III})$-rich sediments at GB ( 0 and $2 \mathrm{~m}$ ) and FR (FR 0, 3, and $10 \mathrm{~m}$ ), partial 16S rRNA gene sequences from these sampling locations were recovered from the RISA gel and analyzed in more detail using the Ribosomal Database Project (RDP) II's classifier function. Phylotypes attributable to the Actinobacteria (59\%) and Gammaproteobacteria $(28 \%)$ were most abundant in the source and Fe(III)-rich sediments of the FR system (Figure 3). Phylotypes attributable to the Chloroflexi (74\%) were most abundant in the source and Fe(III)-rich sediments of the GB system (Figure 3). Actinobacterial phylotypes recovered from the FR system (and one from the GB system) were members of the Acidimicrobiales subclass (Figure 4). The Acidimicrobiales consist of several acidophilic Fe(II)OB, including the heterotrophic Fe(II)OB Ferrimicrobium acidiphilum (Lane et al., 1992; Clark and Norris, 1996; Johnson and Roberto, 1997; Johnson et al., 2003; Druschel et al., 2004; Hallberg and Johnson, 2005; Hallberg et al., 2006). Gammaproteobacterial phylotypes recovered from the FR system were members of the orders Chromatiales, Legionellales and Xanthomonadales (Figure 5). Of these, phylotypes attributable to the Xanthomonadales were most abundant in the FR system and were also detected in the GB system (Figure 5). Xanthomona- 


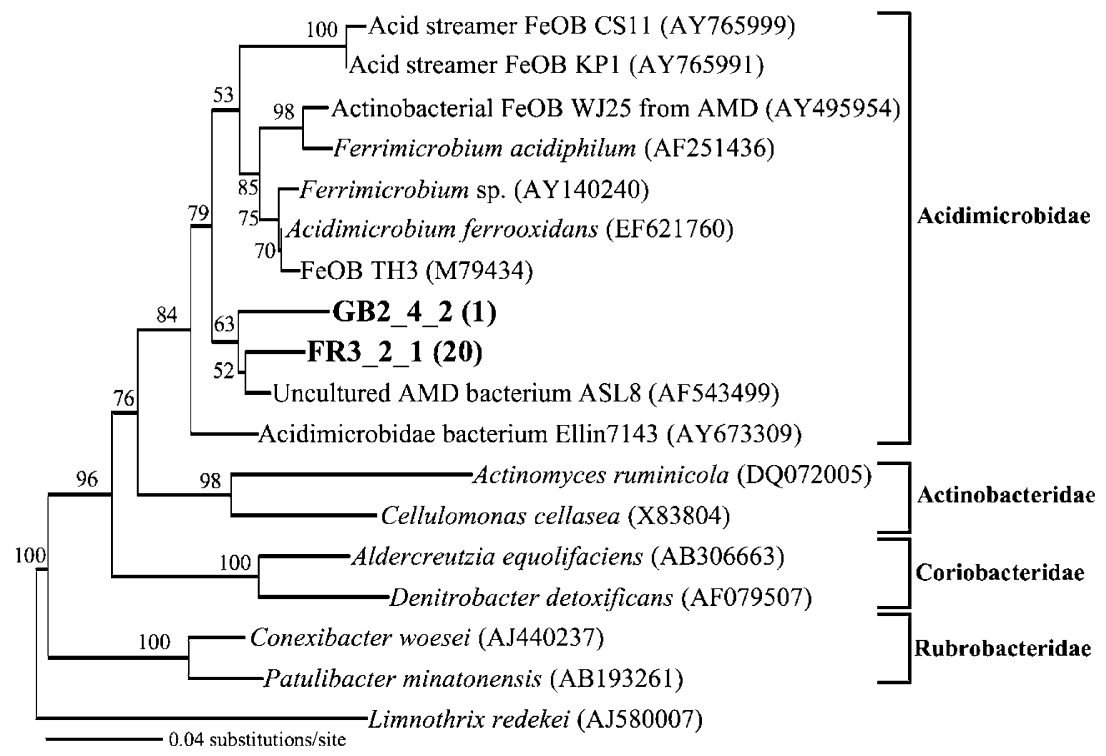

Figure 4 Neighbor-joining tree showing phylogenetic relationship between Actinobacterial sequences recovered from RISA (Figure 4) and selected Actinobacterial sequences from GenBank. Sequences recovered from the RISA gel are in bold font. Numbers in parentheses (besides GenBank accession numbers) represent the frequency of occurrence of a given OTU. Bootstrap values (\%) were determined on the basis of results for 1000 replicates and are shown for branches with more than $50 \%$ bootstrap support.
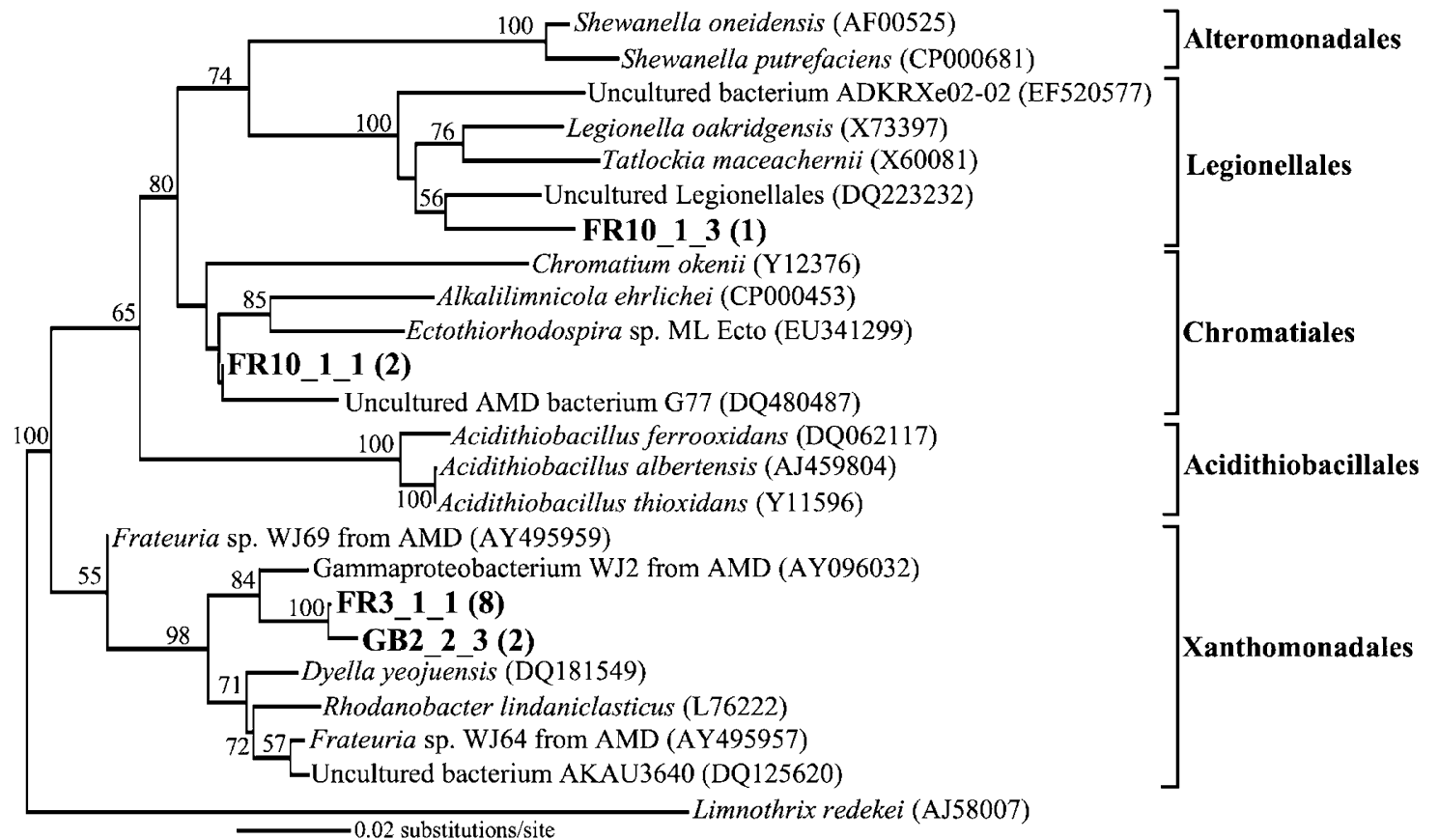

Figure 5 Neighbor-joining tree showing phylogenetic relationship between $\gamma$-proteobacterial sequences recovered from RISA (Figure 4 ) and selected $\gamma$-proteobacterial sequences from GenBank. Sequences recovered from the RISA gel are in bold font. Numbers in parentheses (besides GenBank accession numbers) represent the frequency of occurrence of a given OTU. Bootstrap values (\%) were determined on the basis of results for 1000 replicates and are shown for branches with more than $50 \%$ bootstrap support.

dales-affiliated 16S rRNA gene sequences were most closely related to strain WJ2 (Figure 5), a moderately acidophilic (isolated at $\mathrm{pH}$ 4.5), heterotrophic Fe(II)OB (Hallberg and Johnson, 2003). It is notable that none of the Gammaproteobacterial phylotypes that we recovered from the RISA gel were affiliated with the Acidithiobacillales, the order that includes the relatively well-characterized acidophilic, autotrophic Fe(II)OB Acidithiobacillus ferrooxidans (Figure 5), despite the fact that this organism was cultured from GB sediments. The lack of Acidithiobacillales-like sequences in the RISA bands is likely 


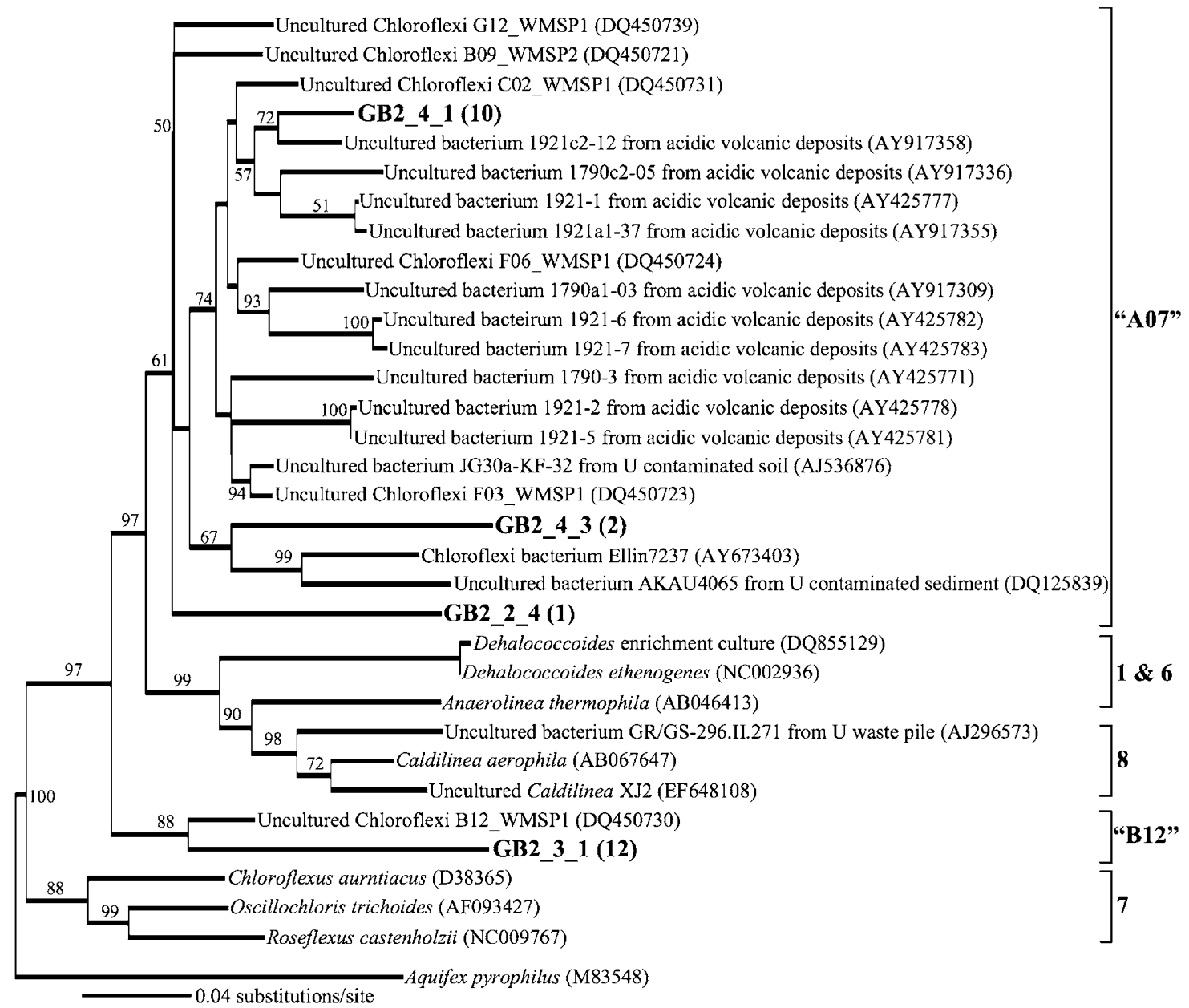

Figure 6 Neighbor-joining tree showing phylogenetic relationship between Chloroflexi bacterial sequences recovered from RISA (Figure 4) and selected Chloroflexi bacterial sequences from GenBank. Sequences recovered from the RISA gel are in bold font. Numbers in parentheses (besides GenBank accession numbers) represent the frequency of occurrence of a given OTU. Bootstrap values (\%) were determined on the basis of results for 1000 replicates and are shown for branches with more than $50 \%$ bootstrap support.

due to the fact that RISA bands were generated with 'universal bacterial' primers (Lane, 1991), which would not be likely to amplify genomes from populations representing $<1 \%$ of the total bacterial community (Borneman et al., 1996).

Although members of evolutionary lineages of organisms known to be capable of Fe(II) oxidation (that is Actinobacteria and Gammaproteobacteria) were present in sampling locations receiving unaltered AMD at the GB site (GB 0 and $2 \mathrm{~m}$ ), Chloroflexi phylotypes outnumbered them in the clone library from this site (Figure 3). The Chloroflexi are a phylum that to our knowledge does not contain acidophilic or Fe(II) oxidizing members, and their potential role in the GB system is unclear. None of the phylotypes recovered from the GB system were affiliated with the Chloroflexi subgroups proposed by Rappé and Giovannoni (2003) (Figure 6). Rather, they were affiliated with the B12 and A07 subgroups proposed by Costello and Schmidt (2006) (Figure 6). These new Chloroflexi subgroups were first observed in saturated tundra soil (Costello and
Schmidt, 2006), and subsequently identified in young, acidic volcanic deposits (Gomez-Alvarez et al., 2007), and uranium-contaminated soils and sediments (Selenska-Pobell et al., 2001; Brodie et al., 2006). The lone cultured representative of the A07 group of Chloroflexi (Chloroflexi bacterium Ellin7237) is an organoheterotrophic bacterium isolated from pasture soil and is characterized by slow growth (up to 12 weeks for colony formation; Davis et al., 2005). The reason for abundance of Chloroflexi phylotypes in the GB system, but not in the FR system is unclear, but may be attributed to physical differences between the two sites such as water temperature (Supplementary Figure S3), flow rate (Table 1) or other factors.

\section{Implications for low $\mathrm{pH} \mathrm{Fe}(\mathrm{II})$ removal from $A M D$}

Our results suggest that when systems are challenged with AMD, bacterial communities develop which have the potential to mediate efficient oxidative precipitation of Fe from AMD. While the 
role of Chloroflexi in the GB system is uncertain, other phylotypes belonging to evolutionary lineages known to be capable of $\mathrm{Fe}$ (II) oxidation were detected in both the GB and FR systems. Previous studies have implicated the autotrophic Fe(II)OB $A$. ferrooxidans, Leptospirillum ferrooxidans and related organisms in the oxidative precipitation of $\mathrm{Fe}(\mathrm{II})$ in AMD treatment systems (Coupland and Johnson, 2004; Nicormat et al., 2006a, b). In studies similar to the ones we present here, $A$. ferrooxidans has been cultured from AMD-impacted sediments (Casiot et al., 2003), but was subsequently shown in culture-independent studies to comprise a minor fraction of $\mathrm{Fe}$ (II)OB-related phylotypes (Bruneel et al., 2006). The work presented here and by others suggest that organisms other than $A$. ferrooxidans and $L$. ferrooxidans may play a prominent role in oxidative precipitation of dissolved Fe(II) from AMD (Casiot et al., 2003; Hallberg and Johnson, 2003; Morin et al., 2003; Bruneel et al., 2006). Hallberg and Johnson (2003) point out that the $\mathrm{pH}$ of the of AMD-impacted systems may influence the composition of $\mathrm{Fe}(\mathrm{II}) \mathrm{OB}$ communities, with relatively low $\mathrm{pH}(<3.0)$ favoring the growth and activity of $A$. ferrooxidans and L. ferrooxidans, and relatively high $\mathrm{pH}(>3.0)$ favoring the growth and activity of 'moderately acidophilic' Fe(II)OB that are phyolgenetically related to organisms that we detected in the GB and FR systems. Although the Actinobacteria and Gammaproteobacteria (including A. ferrooxidans) that we have detected in the GB and FR systems are closely related to known acidophilic Fe(II)OB (Johnson and Roberto, 1997; Hallberg and Johnson, 2003; Johnson et al., 2003; Druschel et al., 2004; Hallberg and Johnson, 2005; Hallberg et al., 2006), we definitively cannot assign Fe(II) oxidizing activity in the GB and FR systems to these organisms. However, this work does suggest that oxidative precipitation of $\mathrm{Fe}(\mathrm{II})$ may be mediated by diverse groups of organisms, several of which have only recently been identified as Fe(II)OB and are poorly characterized. We also point out that we have not assessed the role of archaea in the GB and FR systems, though previous studies have suggested that bacteria predominantly mediate $\mathrm{Fe}(\mathrm{II})$ oxidation in moderately acidic systems (Baker and Banfield, 2003; Hallberg et al., 2006; Nicormat et al., 2006b).

Bacterial communities capable of efficient removal of $\mathrm{Fe}$ (II) from AMD are present in both the GB and FR systems. However, the lack of $\mathrm{O}_{2}$ availability appears to limit the abundance of $\mathrm{Fe}(\mathrm{II}) \mathrm{OB}$ and rates of $\mathrm{Fe}(\mathrm{II})$ oxidation, leading to inefficient removal of $\mathrm{Fe}$ (II) at the FR system. To efficiently remove $\mathrm{Fe}(\mathrm{II})$ from AMD, we envision treatment systems called 'aeration terraces' that could maximize the $\mathrm{O}_{2}$ concentration in AMD, mimic the sheet-like water flow of the GB and FR systems, and maximize residence time. Wetlands are a traditional method for oxidative precipitation of $\mathrm{Fe}$ from AMD, and are attractive because wetland vegetation enhances residence time and retains
Fe(III) (hydr)oxides (Kirby et al., 1999; Johnson and Hallberg, 2005). However, due to the inherently high productivity of wetlands (with the subsequent degradation of organic matter), anoxic zones develop where $\mathrm{Fe}(\mathrm{II})$ oxidation is limited and the reduction of $\mathrm{Fe}(\mathrm{III})$ (hydr)oxides by anaerobic bacteria may lead to the re-release of Fe(II) (Tarutis et al., 1992; Vile and Wieder, 1993; Tarutis and Unz, 1995; Johnson and Hallberg, 2002). By designing AMD treatment systems that mimic the GB system, the $\mathrm{O}_{2}$-dependent limitations on $\mathrm{Fe}(\mathrm{II})$ oxidation may be alleviated.

\section{Acknowledgements}

We thank Pam Milavec and Jon Smoyer from the Pennsylvania Department of Environmental Protection for directing us to the Gum Boot and Fridays-2 systems. We thank Dr D Barrie Johnson from the University of Wales, Bangor for advice in preparing the solid medium for iron-oxidizing bacteria. We thank Richard Unz for critically reviewing the article and providing valuable suggestions. This work was supported by the Pennsylvania Department of Environmental Protection, Bureau of Abandoned Mine Reclamation, the Pennsylvania Water Resources Research Center and the Center for Environmental Chemistry and Geochemistry at the Pennsylvania State University. ML was supported by the National Science Foundation under Grant No. CHE-0431328 and the US Department of Energy, Biological and Environmental Research (BER).

\section{References}

Altschul SF, Madden TL, Schäffer AA, Zhang J, Zhang Z, Miller W et al. (1997). Gapped BLAST and PSI-BLAST: a new generation of protein database search programs. Nucl Acid Res 25: 3389-3402.

Atlas RM. (2004). Handbook of Microbiological Media, 3rd edn. CRC Press: New York, New York, USA.

Baker BJ, Banfield JF. (2003). Microbial communities in acid mine drainage. FEMS Microbiol Ecol 44: 139-152.

Borneman J, Skroch PW, O'Sullivan KM, Palus JA, Rumjanek NG, Jansen JL et al. (1996). Molecular microbial diversity of an agricultural soil in Wisconsin. Appl Environ Microbiol 62: 1935-1943.

Brake SS, Hasiotis ST, Dannelly HK, Connors KA. (2002). Eukaryotic stromatolite builders in acid mine drainage: implications for Precambrian iron formations and oxygenation of the atmosphere? Geology 30: 599-602.

Brodie EL, DeSantis TZ, Joyner DC, Baek SM, Larsen JT, Anderson GL et al. (2006). Application of a highdensity oligonucleotide microarray approach to study bacterial population dynamics during uranium reduction and reoxidation. Appl Environ Microbiol 72: 6288-6298.

Bruneel O, Duran R, Casiot C, Elbaz-Poulichet F, Personné J-C. (2006). Diversity of microorganisms in Fe-As-Rich acid mine drainage waters of Carnoulès, France. Appl Environ Microbiol 72: 551-556.

Casiot C, Morin G, Juillot F, Bruneel O, Personné J-C, Leblanc $\mathrm{M}$ et al. (2003). Bacterial immobilization of 
arsenic in acid mine drainage (Carnoulès creek, France). Wat Res 37: 2929-2936.

Castillo-Gonzalez HA, Bruns MA. (2005). Dissimilatory iron reduction and odor abatement by biofilm communities in swine manure microcosms. Appl Environ Microbiol 71: 4972-4978.

Clark DA, Norris PR. (1996). Acidimicrobium ferrooxidans gen. nov., sp. nov.: mixed-culture ferrous iron oxidation with Sulfobacillus species. Microbiology 142: 785-790.

Cole JR, Chai B, Marsh TL, Farris RJ, Wang Q, Kulam SA et al. (2003). The Ribosomal Database Project (RDP-II): previewing a new autoaligner that allows regular updates and the new prokaryotic taxonomy. Nucleic Acids Res 31: 442-443.

Costello EK, Schmidt SK. (2006). Microbial diversity in alpine tundra wet meadow soil: novel Chloroflexi from a cold, water saturated environment. Environ Microbiol 8: 1471-1486.

Coupland K, Johnson DB. (2004). Geochemistry and microbiology of an impounded subterranean acidic water body at Myndd Parys, Anglesey, Wales. Geobiology 2: 77-86.

Cravotta III CA, Brady KBC, Rose AW, Douds JB. (1999). Frequency distribution of the $\mathrm{pH}$ of coal-mine drainage in Pennsylvania. Water-Resources Investigations Report (United States Geological Survey) 99-4018A, USGS Toxic Substances Hydrology Program. 1: 313-324.

Cravotta III CA. (2008). Dissolved metals and associated constituents in abandoned coal-mine discharges, Pennsylvania, USA. Part 1: Constituent quantities and correlations. Appl Geochem 23: 166-202.

Cravotta III CA, Trahan MK. (1999). Limestone drains to increase $\mathrm{pH}$ and remove dissolved metals from acidic mine drainage. Appl Geochem 14: 581-606.

Davis KER, Joseph SJ, Janssen PH. (2005). Effects of growth medium, inoculum size, and incubation time on culturability and isolation of soil bacteria. Appl Environ Microbiol 71: 826-834.

Dempsey BA, Roscoe HC, Ames R, Hedin R, Jeon B-H. (2001). Ferrous oxidation chemistry in passive abiotic systems for the treatment of mine drainage. Geochem: Exploration Environ Analysis 1: 81-88.

Drummond AJ, Ashton B, Cheung M, Heled J, Kearse M, Moir R et al. (2007). Geneious v3.0. Available from http://www.geneious.com/.

Druschel GK, Baker BJ, Gihring TM, Banfield JF. (2004). Acid mine drainage biogeochemistry at Iron Mountain, California. Geochem Trans 5: 13-32.

Gomez-Alvarez V, King GM, Nüsslein K. (2007). Comparative bacterial diversity in recent Hawaiian volcanic deposits of different ages. FEMS Microbiol Ecol 60: 60-73.

Hallberg KB, Coupland K, Kimura S, Johnson DB. (2006). Macroscopic streamer growths in acidic, metal-rich mine waters in North Wales consist of novel and remarkably simple bacterial communities. Appl Environ Microbiol 72: 2022-2030.

Hallberg KB, Johnson DB. (2003). Novel acidophiles isolated form moderately acidic mine drainage waters. Hydrometallurgy 71: 139-148.

Hallberg KB, Johnson DB. (2005). Microbiology of a wetland ecosystem constructed to remediate mine drainage from a heavy metal mine. Sci Tot Environ 338: $53-56$.

Herlihy AT, Kaufmann PR, Mitch ME. (1990). Regional estimates of acid mine drainage impact on streams in the Mid-Atlantic and Southeastern United States. Wat Air Soil Pollut 50: 91-107.

Johnson DB. (1995). Selective solid media for isolating and enumerating acidophilic bacteria. J Microbiol Meth 23: 205-218.

Johnson DB, Hallberg KB. (2002). Pitfalls of passive mine water treatment. Re/Views in Environ Sci Bio/Technol 1: 335-343.

Johnson DB, Hallberg KB. (2005). Acid mine drainage remediation options: a review. Sci Tot Environ 338: $3-14$.

Johnson DB, Okibe N, Roberto FF. (2003). Novel thermoacidophilic bacteria isolated from geothermal sites in Yellowstone National Park: physiological and phylogenetic characteristics. Arch Microbiol 180: 60-68.

Johnson DB, Roberto FF. (1997). Heterotrophic acidophiles and their roles in the bioleaching of sulfide minerals. In: Rawlings DE (ed). Biomining: Theory, Microbes and Industrial Processes. RG Landes Co.: New York, NY, pp 259-279.

Kirby CS, Thomas HM, Southam G, Donald R. (1999). Relative contributions of abiotic and biological factors in Fe(II) oxidation in mine drainage. Appl Geochem 14: $511-530$.

Lane DJ. (1991). 16S/23S rRNA sequencing. In: Stackebrandt E, Goodfellow M (eds). Nucleic Acid Techniques in Bacterial Systematics. Wiley: New York, NY, pp 115-175.

Lane DJ, Harrison AP, Stahl D, Pace B, Giovannoni SJ, Olsen GJ et al. (1992). The evolutionary relationships among sulfur- and iron-oxidizing eubacteria. J Bacteriol 174: 269-278.

Lovley DR, Phillips EJP. (1987). Rapid assay for microbially reducible ferric iron in aquatic sediments. Appl Environ Microbiol 53: 1536-1540.

Morin G, Juillot F, Casiot C, Bruneel O, Personné J-C, Elbaz-Poulichet F et al. (2003). Bacterial formation of Tooeleite and mixed arsenic(III) or arsenic(V)-iron(III) gels in the Carnoulès acid mine drainage, France. $A$ XANES, XRD, and SEM study Environ Sci Technol 37: 1705-1711.

Nengovhela NR, Strydom CA, Maree JP, Greben HA. (2004). Chemical and biological oxidation of iron in acid mine water. Mine Wat Environ 23: 76-80.

Nicormat D, Dick WA, Tuovinen OH. (2006a). Assessment of the microbial community in a constructed wetland that receives acid coal mine drainage. Microbial Ecol 51: 83-89.

Nicormat D, Dick WA, Tuovinen OH. (2006b). Microbial populations identified by fluorescence in situ hybridization in a constructed wetland treating acid mine drainage. J Environ Qual 35: 1329-1337.

Olem H, Unz RF. (1977). Acid mine drainage treatment with rotating biological contactors. Biotechnol Bioeng 19: 1475-1491.

Park B, Dempsey BA. (2005). Heterogeneous oxidation of $\mathrm{Fe}(\mathrm{II})$ on ferric oxide at neutral $\mathrm{pH}$ and a low partial pressure of $\mathrm{O}_{2}$. Environ Sci Technol 39: 6494-6500.

Pennsylvania Department of Environmental Protection (PA-DEP) (1999). The Science of Acid Mine Drainage and Passive Treatment. PA-DEP publication, Bureau of Abandoned Mine Reclamation, Harrisburg, PA.

Rappé MS, Giovannoni SJ. (2003). The uncultured microbial majority. Ann Rev Microbiol 57: 369-394.

Rose AW, Bisko D, Daniel A, Bower MA. (2004). An 'autopsy' of the failed Tangascootak \#1 vertical flow pond. Proceedings of the National Meeting of the 
American Society of Mining and Reclamation and the 25th West Virginia Surface Mine Drainage Task Force. Published by ASMR, Lexington KY.

Selenska-Pobell S, Kampf G, Flemming K, Radeva G, Satchanska G. (2001). Bacterial diversity in soil samples from two uranium waste piles as determined by rep-APD, RISA, and $16 \mathrm{~S}$ rDNA retrieval. Antonie van Leeuwenhoek 79: 149-161.

Shiller AM, Stephens TH. (2005). Microbial manganese oxidation in the lower Mississippi River: methods and evidence. Geomicrobiol J 22: 117-125.

Stumm W, Morgan JJ. (1996). Aquatic Chemistry. Wiley-Interscience, Hoboken, New Jersey, USA.

Tamura H, Goto K, Yotsuynagi T, Nagayama M. (1974). Spectrophotometric determination of iron(II) with 1,10-phenanthroline in the presence of large amounts of iron(III). Talanta 21: 314-318.

Tarutis Jr WJ, Unz RF. (1995). Iron and manganese release in coal mine drainage wetland microcosms. Wat Sci Technol 32: 187-192.

Tarutis Jr WJ, Unz RF, Brooks RP. (1992). Behavior of sedimentary $\mathrm{Fe}$ and $\mathrm{Mn}$ in a natural wetland receiving acidic mine drainage, Pennsylvania USA. Appl Geochem 7: 77-85.
Tebo BM. (1991). Manganese(II) oxidation in the suboxic zone of the Black Sea. Deep-Sea Res 38: S883-S905.

Thompson JD, Higgins DG, Gibson TJ. (1994). CLUSTAL W: improving the sensitivity of progressive multiple sequence alignment through sequence weighting, positions-specific gap penalties and weight matrix choice. Nucl Acids Res 22: 4673-4680.

Unz RF, Olem H, Wichlacz BS. (1979). Microbiological ferrous iron oxidation in acid mine drainage. Process Biochem 14: 2-6, 28.

Vile MA, Wieder RK. (1993). Alkalinity generation by iron(III) reduction versus sulfate reduction in wetlands constructed for acid mine drainage treatment. Wat Air Soil Pollut 69: 425-441.

Wang Q, Garrity GM, Tiedje JM, Cole JR. (2007). Naïve Bayesian classifier for rapid assignment of rRNA sequences into the new bacterial taxonomy. Appl Environ Microbiol 73: 5261-5267.

Weaver KR, Lagnese KM, Hedin RS. (2004). Technology and design advances in passive treatment system flushing. Proceedings of the National Meeting of the American Society of Mining and Reclamation and the 25th West Virginia Surface Mine Drainage Task Force. Published by ASMR, Lexington KY.

Supplementary Information accompanies the paper on The ISME Journal website (http://www.nature.com/ismej) 